\title{
Meningitis aguda posterior a vacuna tresvírica
}

\author{
Juan Contreras ${ }^{1}$, Pablo Reyes ${ }^{1,2}$ y Claudia P. Cortés ${ }^{1,2}$
}

\footnotetext{
'Facultad de Medicina, Universidad de Chile. Santiago, Chile. ${ }^{2}$ Clínica Santa María, Santiago,

Los autores declaran no tener

conflictos de interés. No se recibió financiamiento.

Recibido: 2 de abril de 2019 Aceptado: 15 de octubre de

\section{Acute meningitis following mumps vaccine}

In Chile, the strain of the mumps virus used in the vaccine is Leningrad-Zagreb (L-Z). Although the relationship between meningitis and the L-Z strain remains controversial, most of the reported cases have shown a benign course without permanent neurological sequelae. We present a case of a patient who presented an aseptic meningitis three weeks after immunization with a mumps vaccine; and laboratory confirmation showed positive serum mumps IgM antibody. In this clinical case, there was a temporal relationship between vaccination and the onset of the mumps and subsequently the meningeal involvement; the immunoglobulin curve demonstrates acute infection after vaccination. Although it was not possible to isolate the virus in CSF, it is reasonable to attribute the picture to a post-vaccinal infection.

Key words: Aseptic meningitis; mumps vaccine; MMR; L-Zagreb mumps strain post vaccine reaction.

Palabras clave: Meningitis aséptica; vacuna tresvírica; SPR; cepa parotiditis L-Zagreb; reacción post-vacuna.

\section{Introducción}

$\mathrm{E}$ 1 virus parotídeo es un virus ARN con envoltura, perteneciente al género Rubulavirus, de la familia Paramyxoviridae. Se transmite por vía respiratoria por inhalación, contacto oral por gotas o secreciones respiratorias infectadas ${ }^{1}$. Alrededor de $30 \%$ de las infecciones por el virus de la parotiditis permanece asintomática o sólo causa síntomas inespecíficos ${ }^{2}$. En la mayoría de los pacientes se desarrolla una inflamación característica unilateral o bilateral de las glándulas parótidas; este aumento de volumen persiste por 2 a 10 días y luego se resuelve espontáneamente ${ }^{3}$. Además del compromiso parotídeo, pueden producirse complicaciones como meningoencefalitis, hipoacusia, pancreatitis y orquitis ${ }^{4}$. El compromiso del sistema nervioso central (SNC) es la complicación extra-glandular más frecuente, desarrollándose una meningitis entre $1-10 \%$ y encefalitis en $0,1 \%$ de los $\operatorname{casos}^{2}$. No se dispone de tratamiento específico y el uso de inmunoglobulina intravenosa se ha limitado al manejo de las complicaciones como encefalitis post-infecciosa, síndrome de Guillain Barré y púrpura trombocitopénico idiopático ${ }^{2}$.

Para prevenir los problemas clínicos, sociales y económicos asociados a las infecciones por el virus parotídeo se han desarrollado vacunas ${ }^{3}$. En general, las reacciones adversas a las vacunas contra la parotiditis son leves e infrecuentes ${ }^{2,5}$. Reacciones cutáneas locales, fiebre y parotiditis son las reacciones adversas más frecuentes ${ }^{2}$. La meningitis post-vacuna es una complicación infrecuente que se presenta dos a tres semanas después de la administración, sin que exista un consenso claro sobre la definición de esta condición ${ }^{5}$. Presentamos el caso clínico de una mujer que evolucionó con una meningitis aséptica, tres semanas post-inmunización con vacuna tresvírica, y una discusión sobre la relación causal entre meningitis y vacuna del virus parotídeo.

\section{Caso clínico}

Mujer de 42 años, nacida y residente en Chile, sin antecedentes médicos relevantes. Con historial de vacunación según el Programa Nacional de Inmunizaciones (PNI) durante su infancia, con una nueva dosis de vacuna tresvírica (cepa Leningrad-Zagreb) 21 días antes del inicio del cuadro clínico, previo a un viaje al extranjero, siguiendo la recomendación vigente del PNI. Consultó a un otorrinolaringólogo por un aumento de volumen parotídeo izquierdo, doloroso, asociado a sensación febril. Ante el cuadro clínico compatible con una parotiditis se realizó una ecografía que mostró un compromiso difuso de la glándula parótida izquierda, indicándose anti-inflamatorios y clindamicina oral $300 \mathrm{mg}$ tres veces al día, por 10 días. Evolucionó con persistencia de la fiebre y dolor local, agregándose cefalea bifrontal y cervicalgia. Tras cuatro días de iniciado el cuadro consultó en servicio de urgencias, destacando en el examen físico un aumento de volumen en la zona parotídea izquierda, doloroso a la palpación, asociado a una sutil rigidez de nuca, sin compromiso de conciencia ni otro hallazgo en el examen neurológico. La tomografía computada (TC) de cuello demostró cambios inflamatorios del espacio parotídeo izquierdo, posiblemente en el contexto de una parotiditis, 
descartando presencia de colecciones. Se realizó una punción lumbar, obteniéndose un LCR incoloro, transparente, con 52 leucocitos $/ \mathrm{mm}^{3}$ (100\% mononucleares), proteínas $63,5 \mathrm{mg} / \mathrm{dl}$ y glucosa $61,9 \mathrm{mg} / \mathrm{dl}$. Se realizó un panel de meningitis/encefalitis por RPC múltiple FilmArray ${ }^{\circledR}$ en LCR que fue negativo. La detección de anticuerpos y antígeno p24 para VIH, mediante ensayo fluorescente ligado a enzimas (ELISA mediante ELFA), fue negativa y la serología de virus parotídeo $\operatorname{IgG}$ e IgM resultó positiva (IgG ratio 2,0; IgM ratio 1,4 ).

Durante su hospitalización presentó un dolor abdominal transitorio de moderada intensidad, con lipasa en rangos normales. Posteriormente, tuvo dolor y aumento de volumen de la parótida derecha. Tras siete días, evolucionó con disminución progresiva de la cefalea, del dolor facial y disminución del volumen parotídeo.

Según la normativa se notificó como un evento supuestamente atribuido a la inmunización (ESAVI) a la sección de farmacovigilancia en vacunas del Departamento Agencia Nacional de Medicamentos del Instituto de Salud Pública de Chile. Durante el seguimiento se realizó una serología para virus parotídeo de control, doce días después de la primera determinación, objetivándose un aumento en los niveles de IgG e IgM (IgG ratio 3,3; IgM ratio 2,4).

\section{Discusión}

Aunque la infección por el virus parotídeo se considera una enfermedad de curso benigno y limitada a la población infantil, también se presenta en adolescentes y adultos, generalmente con complicaciones más graves que en niños ${ }^{5}$. En adultos existe mayor frecuencia de orquitis y meningitis, mientras que en niños predomina la afectación de las glándulas salivales ${ }^{6}$. La orquiepididimitis, infrecuente antes de la pubertad, se encuentra en 15-30\% de los hombres adultos infectados; la ooforitis se presenta en $5 \%$ de las mujeres post-puberales ${ }^{2}$. Debido a que la vacunación con la vacuna tresvírica se introdujo como parte de la inmunización infantil de rutina, actualmente la mayoría de los casos de parotiditis ocurren en adultos ${ }^{7}$.

Todas las vacunas disponibles contra el virus parotídeo están compuestas por virus vivos atenuados, existiendo formulaciones monovalentes o combinadas ${ }^{2}$. Éstas últimas usualmente con sarampión, parotiditis y rubéola (vacuna SPR o tresvírica) ${ }^{5}$. Al igual que otras vacunas de virus vivos atenuados, no debe administrarse a pacientes con enfermedades febriles graves, cáncer avanzado, inmunodeficiencia congénitas o adquiridas, o mujeres embarazadas $^{8}$. Se han usado más de 10 cepas del virus de la parotiditis para la fabricación de vacunas: Jeryl Lynn, RIT 4385, Urabe, Hoshino, Rubini, Leningrad-3, Leningrad-Zagreb, Miyahara, Torii, NK M-46 y S-125.
Pocas intervenciones de salud pública han evitado más muertes y enfermedades que las vacunas. En los lugares donde se ha logrado establecer una vacunación sistemática, la incidencia de parotiditis se ha reducido significativamente ${ }^{5}$. En Chile, desde la introducción de la vacuna al PNI en 1990, la tasa de incidencia disminuyó desde 224 por 100.000 habitantes en 1988 a 7 por 100.000 habitantes el $2016^{9}$. Una vez establecida la eficacia de la vacuna, la discusión se ha centrado en la seguridad y sus efectos adversos ${ }^{10}$.

Como se mencionó previamente, no existe consenso sobre la definición de meningitis aséptica post-vacuna ${ }^{5}$. Sin embargo, la vacunación entre 15 y 35 días antes del inicio de la meningitis se ha identificado como un factor de riesgo significativo y por lo tanto, se considera una asociación causal ${ }^{11}$. A pesar del gran valor de la relación temporal, para establecer la causalidad es necesario aislar el virus parotídeo en el LCR y/o determinar la cepa responsable mediante análisis por RPC para diferenciarla de la cepa silvestre (wild-type) ${ }^{10,12}$. La tasa de meningitis por virus de la parotiditis post-vacunación varía ampliamente entre distintos estudios ${ }^{5}$ y estos difieren según la cepa utilizada, grupo etario, zona demográfica, definición de caso, tipo de vigilancia (activa o pasiva) y diseño del estudio (retrospectivo o prospectivo). Para la cepa Jeryl Lynn, el fabricante de la vacuna describe una tasa de 1 caso de meningitis aséptica por 1.800 .000 dosis $^{13}$. Un estudio retrospectivo de 10 años realizado en E.U.A con una cohorte de niños de 12 a 23 meses reportó un caso de meningitis aséptica por cada 100.000 dosis de vacuna tresvírica con cepa Jeryl Lynn. En Alemania, se reportó 0,1 casos de meningitis aséptica por 100.000 dosis de vacuna, incluyendo vacunas monovalentes y combinadas con cepa Jeryl Lynn. En un estudio retrospectivo de 115 niños hospitalizados por meningitis aséptica dentro de 30 días post-vacunación con la cepa Leningrad-3 (L-3), se describió una incidencia de un caso de meningitis aséptica por cada 1.000 dosis de vacuna ${ }^{14}$. En Japón, desde que se introdujo la vacuna tresvírica en 1989 , se notificaron varios casos de meningitis aséptica post-vacunación que se atribuyeron a la cepa Urabe Am9 y en 1993 el Ministerio de Salud de Japón decidió retirar la vacuna tresvírica ${ }^{15}$. Se debe tener en cuenta que en Japón incluso los casos leves con fiebre aguda y vómitos se sometieron a punción lumbar diagnóstica, debido a la publicidad de la meningitis asociada con la vacuna tresvírica en ese momento ${ }^{16}$.

En Chile se han utlizado dos cepas vacunales, inicialmente la cepa Urabe-09 (genotipo B) y desde el 2010 se continuó con la cepa L-Zagreb (genotipo N) ${ }^{9}$. La cepa L-Zagreb es altamente inmunogénica, siendo las vacunas que la contienen significativamente menos costosas que las alternativas ${ }^{12}$. Aunque se han reportado tasas de meningitis aséptica más altas con las vacunas que 
contienen la cepa L-Zagreb o Leningrad-3, la evidencia es limitada para la cepa Leningrad-3 y controvertida para la cepa L-Zagreb ${ }^{2}$.

La experiencia inicial con la vacuna de cepa L-Zagreb fue positiva, con una eficacia estimada en $97-100 \%{ }^{17}$, hasta que tres estudios realizados en Brasil tras una campaña de vacunación masiva, suscitaron dudas sobre su seguridad ${ }^{18-20}$. Estos estudios se basaron en una vigilancia pasiva de meningitis aséptica, luego de una vacunación masiva con la vacuna tresvírica y utilizaron para definir la meningitis post-vacunal criterios clínicos y la relación temporal, dejando espacio a dudas en cuanto a la causalidad entre la vacunación con la cepa L-Zagreb y la meningitis $^{12}$. En un esfuerzo por confirmar esta relación, Tesovic y cols. realizaron un estudio prospectivo, estimando una incidencia de 9 por 10.000 dosis de vacuna tresvírica con cepa L-Zagreb. La meningitis post-vacunal se definió por: criterios clínicos (fiebre, vómitos, irritabilidad o cefalea 15 a 35 días después de la vacunación), de laboratorio (pleocitosis linfocítica, tinción de Gram y cultivo bacteriológico de LCR negativos), confirmación virológica de la etiología de la meningitis (cultivo de LCR positivo para el virus de la parotiditis y determinación molecular de la cepa aislada $)^{12}$. En general, los casos reportados de meningitis post-vacunal presentaron un curso benigno, breve y sin secuelas neurológicas ${ }^{2,12}$.

En nuestro caso clínico, existió una relación temporal entre la vacunación, el inicio del cuadro parotídeo y meníngeo. Además, la curva de inmunoglobulinas demuestra una infección aguda posterior a la inmunización. Si bien no se aisló el virus en LCR, consideramos razonable atribuir el cuadro a una infección post-vacunal, dada la importancia de la relación temporal al plantear una asociación causal.

En vista del aumento del número de vacunas disponibles y la mayor capacidad de fabricación, existe la necesidad de mejorar los sistemas de farmacovigilancia en el mundo ${ }^{21}$. Debe considerarse que la pérdida de confianza pública en las vacunas puede conducir a una caída en las tasas de inmunización de la población ${ }^{10}$. El reporte de ESAVI aporta datos fundamentales para garantizar la seguridad de las vacunas y al mismo tiempo, resguardar la confianza de la población en ellas.

\section{Resumen}

En Chile, la cepa del virus parotídeo utilizada en la vacuna es Leningrad-Zagreb (L-Z). Aunque la relación entre meningitis y la cepa L-Z sigue siendo controvertida, la mayoría de los casos reportados han presentado un cuadro de curso benigno y sin secuelas neurológicas. Presentamos el caso de una paciente que tres semanas post-inmunización con la vacuna tresvírica evolucionó con una meningitis aséptica de predominio mononuclear, con serología para IgM positiva contra el virus parotídeo. En este caso clínico, existió una relación temporal entre la vacunación, el inicio del cuadro parotídeo y posteriormente el meníngeo; la curva de inmunoglobulinas demostró una infección aguda posterior a la vacuna. Si bien no se logró aislar el virus en LCR, es razonable atribuir el cuadro a una infección post-vacunal.

\section{Referencias bibliográficas}

1.- Rubin S, Eckhaus M, Rennick L J, Bamford C G, Duprex W P. Molecular biology, pathogenesis and pathology of mumps virus. J Pathol 2015; 235: 242-52. doi: 10.1002/ path.4445.

2.- Hviid A, Rubin S, Muhlemann K. Mumps. Lancet 2008; 371: 932-44. doi: 10.1016/S01406736(08)60419-5.

3.- Principi N, Esposito S. Mumps outbreaks: A problem in need of solutions. J Infect 2018; 76 503-6. doi: 10.1016/j.jinf.2018.03.002.

4.- Dayan G H, Quinlisk M, Parker A A, Barskey A E, Harris M L, Schwartz J M, et al. Recent resurgence of mumps in the United States. N Engl J Med 2008; 358: 1580-9. doi: 10.1056/ NEJMoa0706589.

5.- Bonnet M, Dutta A, Weinberger C, Plotkin S A. Mumps vaccine virus strains and aseptic meningitis. Vaccine 2006; 24 : 7037-45.

6.- Rodríguez-Framil M, Campos-Franco J,
Alende-Sixto R, González-Quintela A. Mumps virus infection in adulthood. Enferm Infecc Microbiol Clin 2006; 24: 469-70.

7.- Wiggers J B, Chan T, Gold W L, MacFadden D R. Mumps in a 27-year-old man. CMAJ 2017; 189: E569-E71. doi: 10.1503/cmaj.161347.

8.- Litman N, Baum S. Chapter 159: Mumps virus. In: Bennett J, Dolin R, Blaser M. Mandell, Douglas, and Bennett's Principles and Practice of Infectious Diseases. $8^{\text {th }}$ ed. Philadelphia: Elsevier/Saunders; 2015: 1942-7.

9.- Departamento de Epidemiología, Ministerio de Salud de Chile. Boletín Epidemiológico Trimestral de Parotiditis (CIE-10 B26). Semana epidemiológica 1 - 39 ( 1 de enero a 29 de septiembre). Chile, 2018. Disponible en: http:// epi.minsal.cl/wp-content/uploads/2018/10/ BET_PAROTIDITIS_OCTUBRE_2018.pdf (Fecha de acceso: 24 de noviembre de 2018).

10.- Schlipkoter U, Muhlberger N, von Kries R, Weil J. Surveillance of measles-mumps-rubella vaccine-associated aseptic meningitis in Germany. Infection 2002; 30: 351-5.
11.- Miller E, Goldacre M, Pugh S, Colville A, Farrington P, Flower A, et al. Risk of aseptic meningitis after measles, mumps, and rubella vaccine in UK children. Lancet 1993; 341: 97982.

12.- Tesović G, Lesnikar V. Aseptic meningitis after vaccination with $\mathrm{L}-$ Zagreb mumps strainvirologically confirmed cases. Vaccine 2006 ; 24: 6371-3.

13.- Nalin D. Mumps vaccine complications: which strain? Lancet 1989; 2: 1396.

14.- Cizman M, Mozetic M, Radescek-Rakar R, Pleterski-Rigler D, Susec-Michieli M. Aseptic meningitis after vaccination against measles and mumps. Pediatr Infect Dis J 1989; 8: 302-8.

15.- Ueda K, Miyazaki C, Hidaka Y, Okada K, Kusuhara K, Kadoya R. Aseptic meningitis caused by measles-mumps-rubella vaccine in Japan. Lancet 1995; 346: 701-2.

16.- Sugiura A, Yamada A. Aseptic meningitis as a complication of mumps vaccination. Pediatr Infect Dis J 1991; 10: 209-13. 
17.- Beck M, Welsz-Malecek R, Mesko-Prejac M, Radman V, Juzbasic M, Rajninger-Miholic M, et al. Mumps vaccine L-Zagreb, prepared in chick fibroblasts. I. Production and field trials. J Biol Stand 1989; 17: 85-90.

18.- Arruda W, Kondageski C. Aseptic meningitis in a large MMR vaccine campaign (590, 609 people) in Curitiba, Parana, Brazil, 1998. Rev Inst Med Trop Sao Paulo 2001; 43 : 301-2.
19.- da Cunha S, Rodrigues L, Barreto M, Dourado I. Outbreak of aseptic meningitis and mumps after mass vaccination with MMR vaccine using the Leningrad-Zagreb mumps strain. Vaccine 2002; 20: 1106-12.

20.- da Silveira C M, Kmetzsch C I, Mohrdieck R, Sperb A F, Prevots D R. The risk of aseptic meningitis associated with the LeningradZagreb mumps vaccine strain following mass vaccination with measles-mumps-rubella vaccine, Rio Grande do Sul, Brazil, 1997. Int J Epidemiol 2002; 31: 978-82.

21.- Perez-Vilar S, Weibel D, Sturkenboom M, Black S, Maure C, Castro J L, et al. Enhancing global vaccine pharmacovigilance: Proofof-concept study on aseptic meningitis and immune thrombocytopenic purpura following measles-mumps containing vaccination. Vaccine 2018; 36: 347-54. doi: 10.1016/j. vaccine.2017.05.012. 